\title{
ANÁLISE DA PRODUÇÃO DE BIOGÁS E METANO A PARTIR DA VINHAÇA GERADA EM PEQUENAS FÁBRICAS DE AGUARDENTE E CACHAÇA
}

\author{
Carla Vieira Serufo - carla.serufo@ meioambiente.mg.gov.br \\ Universidade Federal de Minas Gerais e Fundação Estadual do Meio Ambiente \\ Cláudio Leite de Souza - claudio@desa.ufmg.br \\ Universidade Federal de Minas Gerais \\ Sthephanny Walery Pereira Morais - sthephanny@gmail.com \\ Universidade Federal de Minas Gerais \\ Elias Soares de Souza- elias.souza@meioambiente.mg.gov.br \\ Fundação Estadual do Meio Ambiente
}




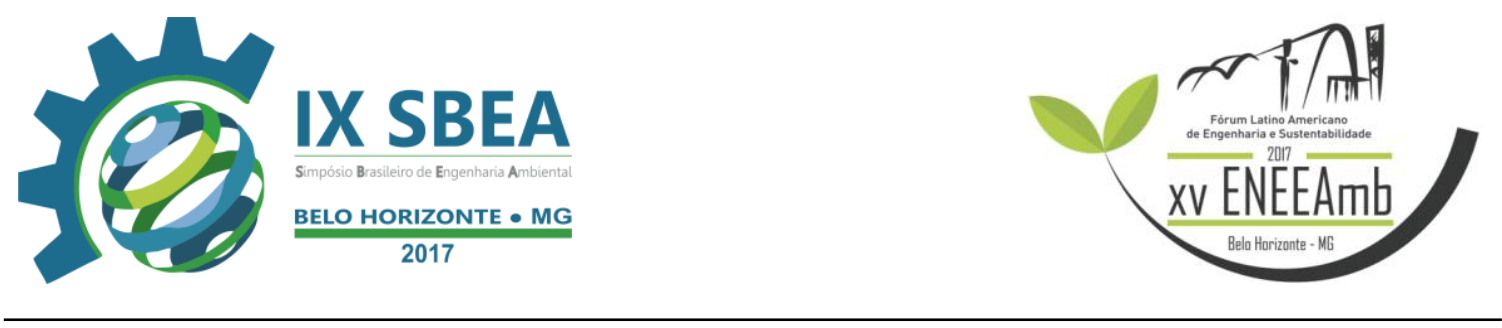

\section{RESUMO}

O objetivo da presente pesquisa foi analisar o potencial da produção de biogás e metano a partir da biodigestão anaeróbia da vinhaça gerada em pequenas propriedades rurais de produção de aguardente artesanal. A tecnologia de biodigestão anaeróbia da vinhaça é uma oportunidade de tornar o processo produtivo mais sustentável, visto que é um investimento em fontes alternativas e descentralizadas de geração de energia. A implantação da tecnologia, portanto, exige cuidados técnicos tais como a motivação do empreendedor em investir no sistema levando-se em consideração a segurança ambiental e a sustentabilidade de sua produção. Foram realizadas análises laboratoriais para avaliação de geração de biogás e metano, a partir da montagem de testes de biodegradabilidade anaeróbia e análise de concentração metanogênica por meio de tecnologia de bancada infravermelha. Foram levados em consideração suas características peculiares - alta taxa de matéria orgânica e baixo pH - e a composição do biogás gerado - elevada produção de gás sulfídrico. Desta maneira, foi possível observar as dificuldades implícitas relativas à essas características e prever possíveis complicações operacionais do sistema. $\mathrm{O}$ alto $\mathrm{pH}$ da vinhaça exige um ajuste, por meio de algum composto químico, de modo que torne o meio ideal e não inóspito ao trabalho bacteriano $(\mathrm{pH}=7)$. A alta taxa de produção de sulfeto, em concentrações tóxicas e prejudiciais aos seres humanas, necessita de um tratamento e purificação do biogás gerado, além de comprometer a integridade dos equipamentos do sistema (biodigestor e motor de geração), por possuir elevada característica corrosiva. Tais resultados indicam para uma maior complexidade da utilização da tecnologia, aumentando, dessa maneira, seus custos de instalação e operação.

Palavras-chave: biodigestão anaeróbia, vinhaça, aguardente artesanal, biogás, metano

\section{INTRODUÇÃO/OBJETIVO}

É fato que as fontes de energia fósseis estão sendo exauridas à medida que a população do planeta vem crescendo, enquanto mudanças nos hábitos de consumo são ainda tímidas e, consequentemente, a demanda por energia se eleva, assim como os impactos ambientais associados. Dessa forma, pesquisas têm sido direcionadas na busca 


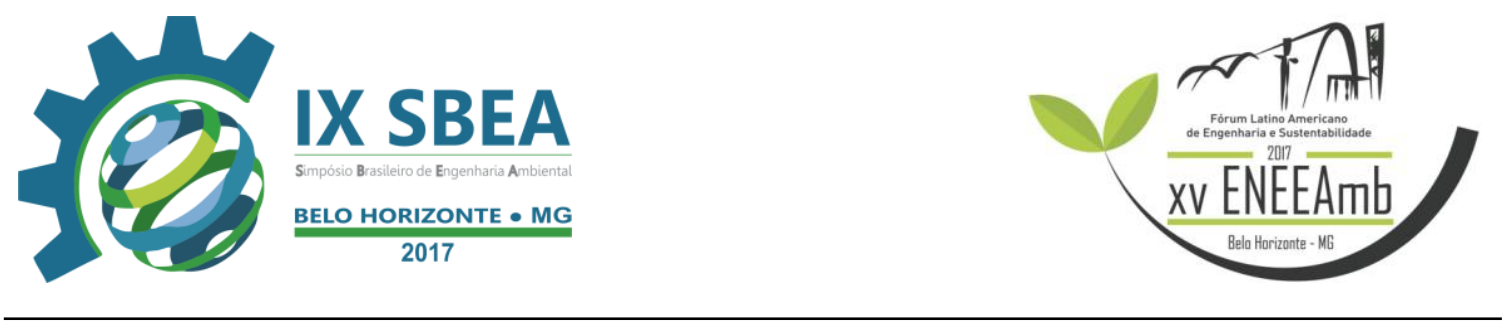

por tecnologias alternativas de fontes energéticas e a utilização da biomassa como matéria-prima ganha cada vez mais evidência (FERNANDES et al, 2007).

A biomassa é uma das fontes alternativas para produção de energia e vem demonstrando elevado potencial de crescimento no mercado internacional e nacional e, por essa razão, pode ser considerada uma das principais alternativas para a diversificação da matriz energética e a consequente redução da dependência dos combustíveis fósseis (SILVA \& CANDIDO, 2015).

O tratamento e o aproveitamento energético de resíduos orgânicos da agroindústria e de indústrias podem ser realizados em biodigestores através da biodigestão anaeróbia que possui como um dos seus subprodutos a parte gasosa, denominada biogás, composto basicamente por metano $(50 \%$ a $75 \%)$ e dióxido de carbono, com capacidade energética média de $5.500 \mathrm{kcal}$ por metro cúbico. O metano $\left(\mathrm{CH}_{4}\right)$ é o principal constituinte do biogás responsável pela sua utilização como recurso energético, quando puro em condições normais (PTN) de pressão (1 atm) e temperatura $\left(0^{\circ}\right)$, tem um poder calorífico inferior $(\mathrm{PCI})$ de $9,9 \mathrm{kWh} / \mathrm{m} 3$. Paralelamente, quando se apresenta em menores porcentagens - entre 50 e $80 \%$ - terá um poder calorífico inferior entre 4,95 e 7,92 kWh/m3(ANEEL, 2005).

A utilização energética do biogás possui como resultado pelo menos uma das seguintes formas de energia: elétrica, térmica ou mecânica. $\mathrm{O}$ aproveitamento energético a partir de pelo menos uma dessas formas de energia proporciona uma poupança de recursos, com importante valor econômico associado. $\mathrm{O}$ uso do biogás gera lucros e economias, fato que desperta um crescente interesse por esta tecnologia (SANTOS, 2000).

Segundo a Agência Nacional de Energia Elétrica (ANEEL), o clima tropical e chuvoso do país, aliado às suas grandes dimensões de terras cultivadas ou cultiváveis, oferece condições ideais para a produção agroindustrial e o uso energético da biomassa em larga escala, com grande potencial no setor de geração de energia elétrica. Entretanto, a utilização da biomassa para produção energética pode ser, também, utilizada em unidades de pequeno porte, isoladas e distantes de centros urbanos, como alternativa de geração de energia para consumo interno. 


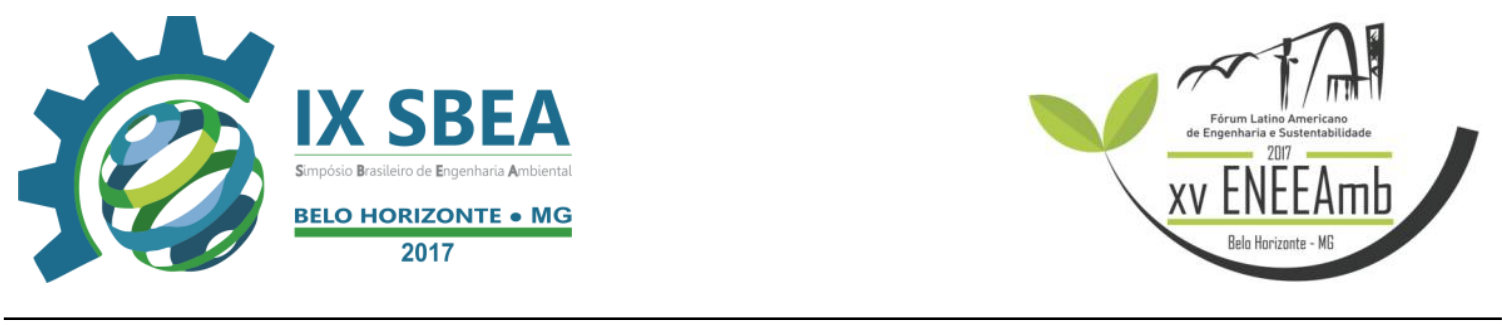

Em visitas realizadas pela FEAM no período de 2005, em fábricas de aguardente, como atividade do projeto "Plano de ação para adequação ambiental do setor de aguardente e cachaça artesanal no estado de Minas Gerais”, nas quais foi respondido pelos produtores o questionário sobre a produção e controle ambiental, a informalidade aliada à inexistência de adoção de boas práticas ambientais foram as constatações mais evidentes. Mesmo nas poucas fábricas em que foi observado que a vinhaça, efluente gerado em grandes quantidades no processo de destilação da aguardente, é disposta em área agrícola, seja em canaviais ou pastagens, esse procedimento é visto apenas como ônus, realizado sem qualquer critério agronômico, sendo mais utilizado como forma de se "livrar do problema", apenas como uma alternativa ao lançamento desse efluente diretamente em curso d'água, evitando-se, assim, as consequências da legislação ambiental (FEAM, 2005).

Dessa forma, a alternativa de controle ambiental, com possível retorno financeiro, mediante a transformação de um efluente em fonte de energia para consumo na propriedade rural, certamente é uma condição aplicável e atraente para pequeno produtor de aguardente. Diante desse contexto, o objetivo deste estudo foi avaliar a qualidade e o potencial metanogênico do biogás proveniente da vinhaça gerada nas fábricas de aguardente e, principalmente, seu uso pelo pequeno produtor rural, uma vez que a utilização da biodigestão, além de proporcionar a obtenção de gás combustível, não altera as características fertilizantes do efluente direcionado à fertirrigação.

\section{METODOLOGIA}

As análises de amostras de vinhaça foram realizadas nos Laboratórios de Análises Físico-química e Microbiologia do Departamento de Engenharia Sanitária e Ambiental da Universidade Federal de Minas Gerais - DESA/UFMG. Por meio de experimentos de biodegradabilidade anaeróbia e monitoramento da produção de biogás, utilizando-se a vinhaça como substrato e o lodo anaeróbio como inóculo, foi possível definir o potencial metanogênico e a taxa de gás sulfídrico no biogás através de tecnologia de bancada infravermelha. A vinhaça foi coletada, em 28/08/2016 no município de Jequitibá, durante visita técnica ao alambique selecionado. O lodo anaeróbio foi obtido de um reator UASB do Centro de Pesquisa e Treinamento em Saneamento UFMG/COPASA (CePTS), Belo 


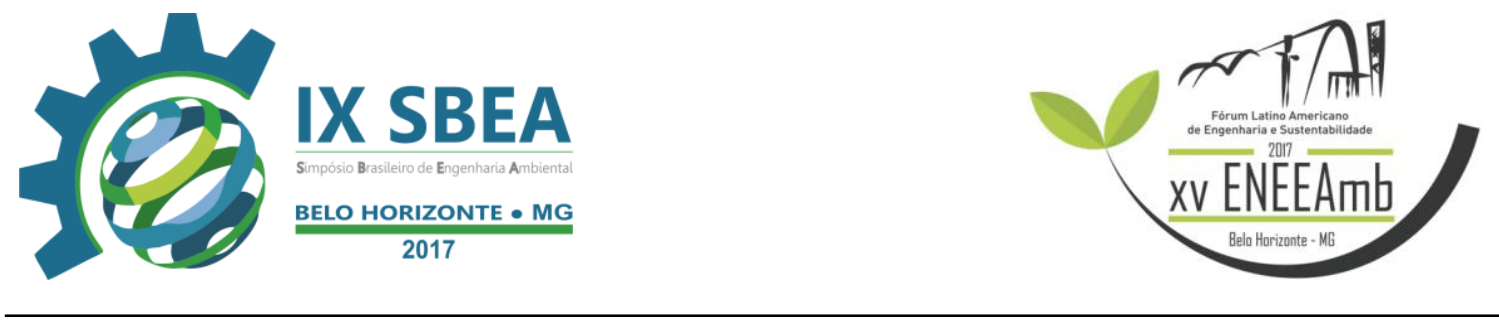

Horizonte - MG. O armazenamento da vinhaça e do lodo anaeróbio foi feito em recipientes de plástico, sob refrigeração a $4^{\circ} \mathrm{C}$, até sua utilização. Os testes foram conduzidos em frascos tipo penicilina de $200 \mathrm{~mL}$, com volume útil de $140 \mathrm{~mL}$ e headspace de no mínino 60 mL (30\% do frasco reservado para geração do biogás).

O trabalho foi desenvolvido em duas etapas. Na primeira etapa, realizou-se uma avaliação físico-química do substrato e inóculo: medição de $\mathrm{pH}$ e definição dos sólidos totais e voláteis. Na segunda etapa foram montados os testes de biodegradabilidade anaeróbia e realizado um monitoramento de produção de biogás e metano.

Sabendo-se que o pH do meio é um fator limitante para o bom funcionamento das diversas etapas do processo anaeróbio, a pesquisa considerou um ajuste de $\mathrm{pH}$, por meio de hidróxido de sódio, de modo a produzir um pH favorável à ação das bactérias metanogênicas. Diante disso, foram propostas três condições para efeito de comparação e análise dos resultados:

$\rightarrow$ Branco: lodo anaeróbio + água

$\rightarrow$ Condição 1: lodo anaeróbio + vinhaça bruta

$\rightarrow$ Condição 2: lodo anaeróbio + vinhaça com ajuste de $\mathrm{pH}$

Todos os testes foram realizados em triplicatas (3 frascos por condição estabelecida) e preservados em incubadora shaker a $30^{\circ} \mathrm{C}$, com agitação de $100 \mathrm{rpm}$. Esses valores foram baseados nas condições operacionais do reator UASB ( Figura 2).

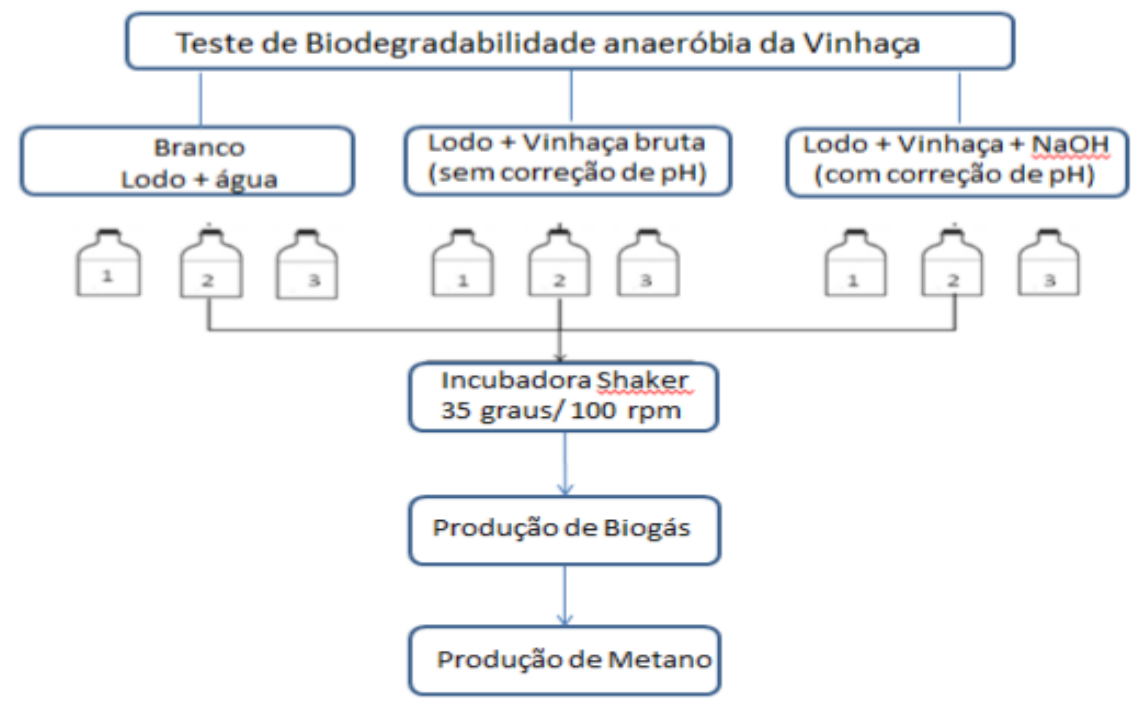

Figura 2 - Desenho esquemático da metodologia utilizada no teste de biodegradabilidade anaeróbia da vinhaça 




Após a montagem de cada frasco, foi realizada uma lavagem com gás nitrogênio com o objetivo de eliminar o oxigênio de dentro do recipiente e propiciar a biodegradação anaeróbia do substrato. As triplicatas foram, então, monitoradas durante um período de 18 dias, por meio de medições volumétricas do biogás produzido e análise da composição desse biogás. As amostras de gases foram submetidas à uma tecnologia de bancada infravermelha por meio do medidor portátil Geotech BIOGAS 5000 para a quantificação de metano $\left(\mathrm{CH}_{4}\right)$ e sulfeto de hidrogênio $\left(\mathrm{H}_{2} \mathrm{~S}\right)$

\section{RESULTADOS E DISCUSSÃO}

Após a caracterização do substrato (vinhaça) e do inóculo (lodo anaeróbio) em termos de Sólidos Totais Voláteis (STV), as quantidades de vinhaça e lodo foram calculadas para cada reator, de forma a estabelecer a relação substrato/inóculo em torno de 0,5. A relação substrato/inóculo foi calculada por meio da Equação(1):

$$
\begin{aligned}
& \qquad \frac{S v \text { amostra }}{\text { Sv inóculo }} \leq 0,5 \\
& \text { Sv amostra - corresponde a quantidade de SV da alíquota da amostra usada no teste } \\
& \text { SVinóculo-corresponde a quantidade de SV da alíquota do inóculo usada no teste. }
\end{aligned}
$$

A partir dos dados obtidos e seguindo as condições estabelecidas pelas concentrações de sólidos nas amostras analisadas, foram definidos os volumes utilizados para a montagem dos testes de biodegradabilidade anaeróbia. De acordo com os resultados foram, então, definidos os volumes de $40 \mathrm{~mL}$ de vinhaça para $60 \mathrm{~mL}$ de lodo anaeróbio (Tabela 1).

Tabela 1 - Definição dos volumes para montagem dos testes de biodegradabilidade: substrato e inóculo

\begin{tabular}{l|c|c|c|c|c|c}
\hline Amostra & $\begin{array}{c}\text { Volume } \\
(\mathbf{m L})\end{array}$ & ST & SV & $\begin{array}{c}\text { Frasco } \\
\mathbf{( g / L )}\end{array}$ & $\%$ & Sva/Svi \\
\hline Vinhaça & 40 & 1,2 & 1,05 & 77,72 & 7,77 & \multirow{2}{*}{0,48} \\
\hline Lodo & 60 & 3,46 & 2,17 & 36,22 & 3,62 & \\
\hline
\end{tabular}

$\mathrm{O}$ pH do lodo anaeróbio medido variou entre 6,8-7,2 e da vinhaça 3,4-3,45. O baixo $\mathrm{pH}$ da vinhaça foi ajustado para o teste, em uma das triplicatas, com intuito de atingir o pH ótimo das bactérias biodigestoras e diferenciar a produção de biogás nos diferentes meios. Os resultados de volume acumulado de gás obtidos dos frascos com 
vinhaça bruta e vinhaça com acréscimo de hidróxido de sódio para ajuste de $\mathrm{pH}$ indicaram diferenças significativas na produção de biogás e metano entre as triplicatas com diferentes $\mathrm{pH}$. O baixo $\mathrm{pH}$ da vinhaça bruta comprometeu a ação dos microorganismos, principalmente das bactérias metanogênicas, visto que as reações enzimáticas que ocorrem durante as etapas metobólicas só acontecem em determinadas faixas de $\mathrm{pH}$. A fase metanogênica ocorre em $\mathrm{pH}$ ideal entre 6,6 e 7,4 e, portanto, confirmou-se o efeito negativo do $\mathrm{pH}$ da vinhaça no meio $(\mathrm{pH}$ da vinhaça $=3,4$ / 3,5), de acordo com a Figura 4 a seguir:
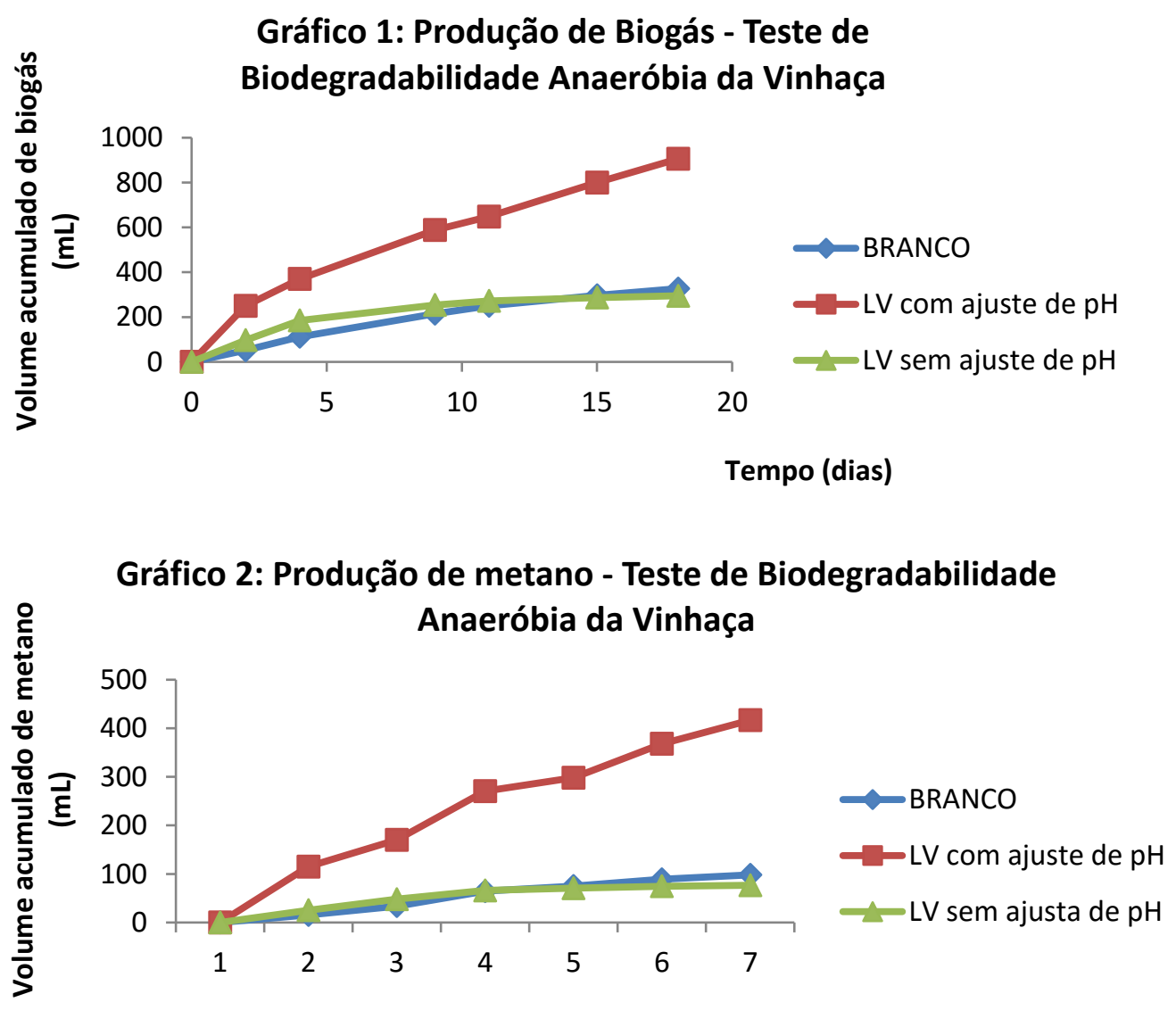

Figura 4 - Gráficos gerados pelos experimentos de bancada laboratorial: análise da produção de biogás e metano

$\mathrm{O}$ pH é um parâmetro essencial para o funcionamento equilibrado do processo anaeróbio. As amostras que não receberam acréscimo de hidróxido de sódio para ajuste de $\mathrm{pH}$ apresentaram como resultado de produção média de biogás um valor próximo de $300 \mathrm{~mL}$, enquanto aquelas submetidas ao ajuste de $\mathrm{pH}$ produziram aproximadamente 900 
$\mathrm{mL}$, apresentando, portanto, uma produção $200 \%$ maior. A produção acumulada de metano $\left(\mathrm{CH}_{4}\right)$ foi ainda mais elevada: as amostras com vinhaça bruta e as que receberam correção de $\mathrm{pH}$, por meio da adição de hidróxido de sódio, apresentaram uma produção média de metano próximo a $80 \mathrm{~mL}$ e $420 \mathrm{~mL}$, respectivamente. Esses resultados indicam que os frascos que receberam o acréscimo da substância química produziram, aproximadamente, $420 \%$ a mais de metano do que os frascos que não receberam o ajuste de $\mathrm{pH}$.

Apesar da diferença significativa desses valores, a utilização de produtos químicos pode ser vista como uma desvantagem para o processo, já que aumenta os custos de operação da tecnologia. É possível, ainda, observar que as amostras de vinhaça bruta acompanham a tendência de produção do branco, o que indica que o substrato vinhaça não está sendo, de fato, utilizado pelas bactérias como alimento. Conclui-se, portanto, que o controle de um $\mathrm{pH}$ ideal para o meio é extremamente importante para garantir a estabilidade dos microrganismos envolvidos, não comprometendo o processo de biodegradação anaeróbia.

De acordo com os estudos de Lange et al. (2002), valores de $\mathrm{pH}$ baixos podem representar elevada concentração de ácidos graxos voláteis, o que pode levar à inibição da atividade afetando o crescimento das bactérias metanogênicas. As análises de gás sulfídrico na composição do biogás produzido no teste apontaram um fator ainda mais complicador para o biodigestão anaeróbia do meio: o baixo $\mathrm{pH}$ do meio gerado pela vinhaça bruta potencializa a produção de altas taxas de gás sulfídrico. Estudos de McCartney e Oleszkiewicz (1991), ressaltam que o equilíbrio químico das espécies de sulfeto é dependente do $\mathrm{pH}$ e, em condições ácidas, prevalece no meio a presença de $\mathrm{H}_{2} \mathrm{~S}$ sob a forma molecular; já em condições básicas, a formação de $\mathrm{H}_{2} \mathrm{~S}$ é inibida e prevalecem as formas ionizadas de sulfeto.

Os resultados apontaram para uma alta produção de gás sulfídrico a partir do tratamento anaeróbio da vinhaça bruta (aproximadamente $1500 \mathrm{ppm}$ ), enquanto os frascos que receberam ajuste de $\mathrm{pH}$ apresentaram taxas mais baixas (320 ppm), um pouco acima do branco (260 ppm), conforme apresentado na tabela abaixo (Tabela 2):

Tabela 2 - Produção média de gás sulfídrico 


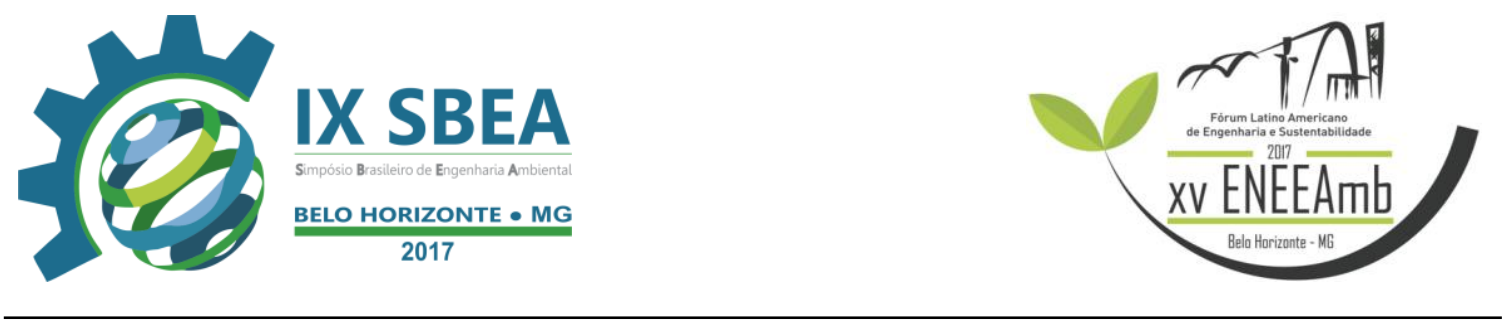

\begin{tabular}{c|c}
\hline Testes & $\begin{array}{c}\text { Produção } \\
\text { média de H2S } \\
\text { (ppm) }\end{array}$ \\
\hline Branco - Lodo + água & 260 \\
\hline Lodo + Vinhaça (com ajuste de $\mathrm{pH})$ & 320 \\
\hline Lodo + Vinhaça (sem ajuste de $\mathrm{pH})$ & 1500 \\
\hline
\end{tabular}

De acordo com Chernicharo (2007), as bactérias responsáveis pelas fases de hidrólise, acidogênese, acetanogênese e sulfetogênese necessitam de pH ideal entre 5 e 6 , enquanto que na fase metanogênica, o crescimento microbiano ótimo ocorre em $\mathrm{pH}$ na faixa de 6,6 e 7,4. Por essa razão, o pH mais baixo favorece as bactérias redutoras de sulfato e consequente formação do gás sulfídrico, além de diminuir a ação das bactérias fermentativas, acetogênicas e metanogênicas, na medida em que competem com os substratos disponíveis no meio.

Por meio das concentrações definidas pelos testes, é possível perceber que o biogás gerado por meio da biodegradação anaeróbia da vinhaça bruta, em meio ácido ( $\mathrm{pH}$ $=3,4-3,5)$ possui uma taxa alta de gás sulfídrico, podendo trazer, de acordo com o Manual de Procedimentos para Auditoria no Setor Saneamento Básico de 2001, efeitos muito graves aos seres humanos, como a inconsciência e a morte durante uma rápida exposição. Dessa maneira, o estudo conclui que, para um possível aproveitamento energético do biogás gerado pela biodegradação anaeróbia da vinhaça, é necessário a implantação de um sistema de purificação do biogás que remova eficientemente o gás sulfídrico gerado. Essa característica resulta, portanto, em um aumento no custo do sistema para o produtor.

Os resultados permitiram observar, portanto, que a vinhaça, apesar de ser um substrato com elevada carga orgânica, possui determinadas características que necessitam de maior atenção durante seu tratamento anaeróbio: o baixo pH e significativo potencial de geração de gás sulfídrico.

\section{CONCLUSÕES/RECOMENDAÇÕES}

A viabilidade de implantação de pequenos biodigestores nas propriedades rurais de produção de aguardente depende de vários fatores e condições. É fato que a geração de energia (térmica e elétrica), por meio de um subproduto gerado em um processo fabril, 


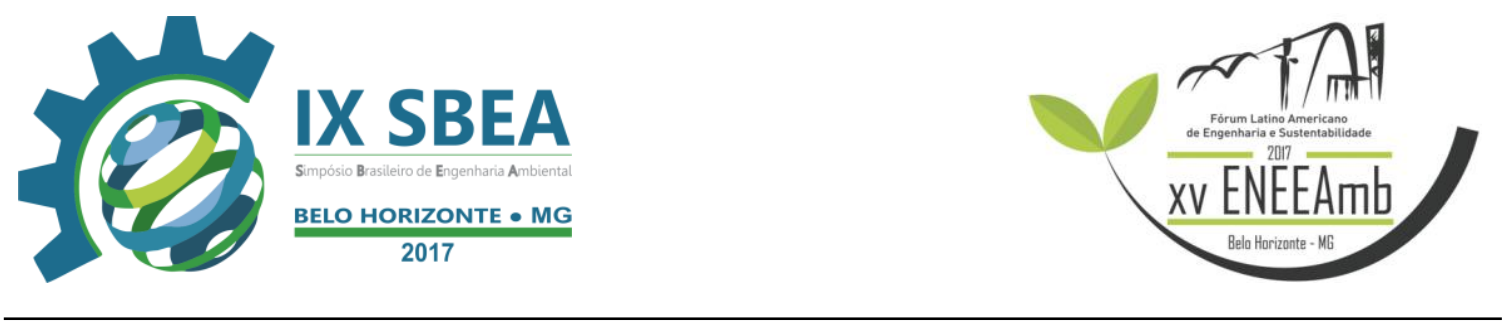

ou seja, um efluente que necessita de uma destinação ambientalmente adequada, reflete em ganhos econômicos e ambientais para o empreendedor.

A vinhaça, muitas vezes descartada incorretamente nos cursos d'àgua, possui alto potencial poluidor. A geração de energia por meio de seu tratamento anaeróbio é uma alternativa sustentável para o produtor. No entanto, como demonstrado nos resultados laboratoriais se, por um lado, a vinhaça possui alta carga orgânica e, por essa razão, alto potencial de produção de biogás, por outro, possui características peculiares que torna esse tipo de tratamento complexo.

$\mathrm{O}$ baixo $\mathrm{pH}$ da vinhaça reflete negativamente no processo de produção metanogênica, já que torna o meio inóspito para as bactérias geradoras de metano. Por essa razão, seria necessário a utilização de produtos químicos adicionais para correção de $\mathrm{pH}$, o que traz custos adicionais para o tratamento, além da possibilidade de causar efeitos negativos na qualidade do produto final, utilizado como biofertilizante.

Outro fator que exige maior atenção é o alto teor de enxofre em sua composição que, aliado às condições do meio torna elevada a produção do gás sulfídrico e, como consequência, confere ao biogás toxicidade ao ser humano e possível potencial corrosivo tanto para o material do biodigestor, quanto para os encanamentos e motor de geração elétrica. Diante disso, para utilização do biogás gerado pela destilação da vinhaça, é necessária uma tecnologia de purificação do gás e remoção do gás sulfídrico, o que também indica um acréscimo de custos.

É importante considerar que a implantação do sistema de produção de biogás por meio do tratamento da vinhaça representa para o produtor trabalho a mais e custo adicional, visto que a maioria deles já utiliza o efluente como fertilizante. Diante disso, é necessário realizar um estudo completo de custo de implantação, operação e manutenção, analisando o tempo de retorno para o produtor e seus respectivos ganhos econômicos, considerando as dificuldades operacionais advindas das características peculiares da vinhaça.

\section{REFERÊNCIAS BIBLIOGRÁFICAS}


ANEEL. AGÊNCIA NACIONAL DE ENERGIA ELÉTRICA. Banco de Informações da Geração do Brasil. Disponível em: < http://www.aneel.gov.br/aplicacoes/ capacidadebrasil/capacidadebrasil.cfm >. Acesso em 18 de eoutubro 2016.

ANEEL. AGÊNCIA NACIONAL DE ENERGIA ELÉTRICA. Legislação/ Regulamentação, referências disponíveis no sítio na internet: http://www.aneel.gov.br . Acesso em 02 de outubro de 2016

FEAM. Cachaça de alambique. Manual de boas práticas ambientais e de produção. 2005

\section{FEAM. FUNDAÇÃO ESTADUAL DO MEIO AMBIENTE. Guia Técnico Ambiental} de Biogás na Agroindústria. Belo Horizonte, 2015. FERNANDES, F. R. C.; LUZ, A. B.; MATOS, G. M. M. CASTILhOS, Z. C.Tendências Tecnológicas Brasil 2015: Geociências e Tecnologia Mineral- Rio de Janeiro: CETEM/MCT, 2007.

GOSTELOW, P.; PARSONS, S.A. Hydrogen sulphide measurement. In: STUETZ, R.; FRECHEN, F.B. Odours in wastewater treatment: Measurement, modelling and control. London: IWA Publishing, 2001. 437p.

GOSTELOW, P.; PARSONS, S.A.; STUETZ, R.M. Odour measurements for sewage treatment works. Water Research, v.35, n.3, p.579-597, 2001.

LANGE, L.C.; SIMÕES, G.F.; FERREIRA, C.F.A.; SANTANA, D.W.E.A.; GARCIA, L.N. Estudo comparativo de metodologias para análises físico-químicas de resíduos sólidos urbanos. In: CASTILHOS JR., A.B.; LANGE, L.C.; GOMES, L.P.; PESSIN, N. (Organ.). Alternativas de disposição de resíduos sólidos urbanos para pequenas comunidades. Rio de Janeiro: ABES, Projeto PROSAB, 2002. 104p.

MCCARTNEY, D. M., OLESZKIEWICZ, J. A., Sulfideinhibition of anaerobic degradation of lactate and acetate, Water Research.,Vol. 25 (2), pp. 203-209, 1991.

MTE. MiNiStÉRIO DO TRABALHO E EMPREGO. Manual de Procedimentos para Auditoria no Setor Saneamento Básico. Secretaria de Inspeção do Trabalho.Departamento de Segurança e Saúde no Trabalho. Novembro de 2002

SANTOS, P. Guia Técnico de Biogás. CCE - Centro para a Conservação de Energia, Portugal, 2000.

SILVA, S. S. F. 1; CÂNDIDO, G. A. Matriz energética limpa e renovável: um desafio para o Planejamento Energético Nacional e uma oportunidade para a Região Nordeste do Brasil. Revista Espacio, Caracas, Venezuela.Vol. 36 (N 15) Ano 2015tugal, 2000 